\title{
Innovation in Rural Development - Bottom up Approach of Leadership to empowerpoor farmers
}

\author{
The Blue Revolution Pioneer, Dr M.V.Gupta, Prof Suryakumari Duggirala ${ }^{1}$, \\ Dr Vinayak S Deshpande ${ }^{2}$, Dr Sneha V Deshpande ${ }^{3}$ \\ ${ }^{I}$ Visiting Faculty, Indian Maritime University, Chennai, India \\ PhD Scholar, Deptt of Economics RTM Nagpur University, Nagpur, India \\ ${ }^{2}$ Dean - Faculty of Commerce and Management RTM Nagpur University, Nagpur, India \\ ${ }^{3}$ Professor \& Head, Deptt of Economics RTM Nagpur University, Nagpur, India
}

\begin{abstract}
Social Entrepreneurship has been a tool to solving the problems of Food Security. It has been a sustainable development issue linked to economic development, environment and trade: the physical ability to access and the financial capability to afford food to meet people's nutrition and diet in sync with their preferences. Dr M V Gupta, recipient of the World Food Prize in 2005 and the Sunhak Peace Prize in 2014 hailed as the pioneer of the Blue revolution wherein aquaculture and freshwater fish farming as an alternative solution to the food crisis of the future was provided. Working with NGOs, poor women and a bottom-up approach helped in mitigation of poverty, malnutrition and self-reliance. Sustainability issues were addressed effectively and helped poor farmers and rural families in large parts of South and Southeast Asia, covering Bangladesh, India, Vietnam, Thailand, Cambodia, the Lao PDR and Indonesia. The bottom up approach to empower the bottom of the pyramid populace is a sustainable solution by enabling them with relevant skill sets.

Keywords: Social Entrepreneurship, Blue Revolution, Food Security, Bottom-up Approach to Research, NonGovernmental Organizations, Women Empowerment
\end{abstract}

\section{Introduction}

While the top MNCs of the world were trying to sow their products and reap the market in the Tier 2 towns and villages in developing and underdeveloped countries, there was one simple unassuming scientist, enabling and empowering the same population in the villages by providing them with skill sets to be self-reliant and self sufficient. The Blue Revolution Pioneer, Dr Modadugu Vijay Gupta said: "There can be no peace without food security in the world. You cannot talk peace to a hungry man."

A social entrepreneur in the making, Dr Gupta is a visionary with tremendous determination. This may bring to the eye an ambitious person pounding with zeal and drive, the picture of speed, passion and drive, akin to a maverick in a filmy setting. Dr Gupta, on the other hand can be missed in a crowd with his unassuming personality and quiet demeanor. Hidden within the soft-spoken man with very few words, is a person with perseverance to do what he is passionate about - Use his scientific research background to help the poor eradicate hunger and poverty. There is no impatience visible in his mannerisms, which gives one the insight that great things can be done with immense patience and dedication.

Entrepreneurs look into technological innovation to yield the market potential of the rural markets by shaping aspirations and tailoring local solutions. This they do by using resources to develop or innovate from existing products, locally suitable sizes, shapes and packaging at reduced prices. They also leveraged from the knowledge from one country or locale to another. Their R\&D focused on the poor and produced products to suit their needs. Lowering their cost structures, creating different employment ratios and even forming new alliances with local firms were part of the package. More important than all of the above, was creating buying power which was the focus of social entrepreneurs like Mohammad Yunus and Modadugu Gupta. Microlending and microfinance were the tools used by Yunus when he formed the Grameen bank. Dr Gupta meanwhile looked towards equipping the poor with income earning skills.

There are different ways to bringing about change for the better:

1. Push/Pull or Trickle down effects of development policies: Most developmental policies revolve around this principle. A particular sector or activity is initiated and in the establishment of that, other peripheral activities get developed automatically. For eg, if a hospital is set up in a remote area, roads, transport, housing, schools and colleges, and other business develops consequently.

2. Integrate the poor into the mainstream markets: Many a time, there is adequate production in the rural areas but the farmer is unable to sell his produce for a good price. Similarly, to produce at lower cost and competitive quality and quantity, the farmer does not have access to good quality and cost effective inputs, 
due to which his produce does not withstand competition. If this is provided, the benefits of marketing and competitive pricing are available to the farmer.

3. Improve the Family's Nutrition needs: It is a combination of non-availability, lack of access, lack of knowledge and poverty that denies the households to eat a healthy and nutritious diet. If this is made possible, then they are in a better position to contribute to the economy.

4. Intra-Household gender equality towards empowerment: When all members of the household are empowered in the streams of education and finances, the dynamics of the family is transformed towards a better decision-making authority by itself. All members of the family are able to contribute to the kitty, and mutual respect amongst members is garnered. This leads to all-round happiness and a responsible household.

5. Higher Yields: Increase in the output leads to higher incomes and ability to eat better, sell better, save better, invest better and live better.

6. Market Linkages: Most developing countries are fraught with middlemen and unscrupulous margins and markets that thwart the direct benefits of increased production to the producer. If the producer-farmer has access to markets or if markets are established at the producer level, meaning direct selling, the margins are minimized and benefits accrue to the producer himself. This leads to better livelihoods of the farmers.

7. Financial access and services: The cost of credit, meaning the cost incurred to provide credit is higher than the actual credit disbursed. This is because the marginal farmer usually requires small amounts, like cash handouts to tide the moment, so to say. This high cost of transaction deters the banking sector to provide adequate credit to the farmer and small-medium entrepreneur. By taking recourse to the tool of microfinance and micro credit and utilizing the services of NGOs, the banks can provide timely credit to improve the lives of the poor farmer.

8. Resource mobilization: In finale, if all the factors for development are possible, then there is no deterrent to increase production and provide a higher level of incomes and livelihoods for themselves. These are what are required to enhance the lives of the poor and integrate them into mainstream population, making them economically and socially independent.

\section{Modadugu Vijay Gupta}

Born in 1939, Gupta began his career in 1962 from the Indian Council of Agricultural Research, ICAR in Kolkata researching on how fish production can bring solace to the Indian farmers. His work in India in early 1970s resulted in breaking the yield barrier in aquaculture, leading to doubling of production, laying the foundation for what we call as "Blue Revolution", which at that time (in 1970s) was termed as "Aquaplosion". $\mathrm{He}$ assessed the physical and social resources that were accessible in the impoverished areas before developing techniques suitable for the poor. First, he trained the poor and landless people in recycling methods. Farm wastes such as rice bran, weeds and manure were used as feed for large fish stock. Next, he taught them the polyculture technique of breeding multiple species of fish in a single pond habitat. This was an effective technique wherein the farmer is able to harvest more varieties of fish with higher nutritional value. This technique resulted in the pioneering research by Dr Gupta and his team, helped poor farmers and rural families in large parts of South and Southeast Asia, covering Bangladesh, India, Vietnam, Thailand, Cambodia, the Lao PDR and Indonesia. They were able to use abandoned ponds, roadside ditches, seasonally flooded fields and any water bodies as small as 300-400 SqMts and make them into "mini factories" of fish, providing income and solace to their families. Eg, 150,000 seasonal ponds in Bangladesh that were unused are now abundant in fish. Dr M V Gupta was the recipient of the World Food Prize in 2005 considered as Nobel Prize in Food and Agriculture and the Sunhak Peace Prize in 2015. He is hailed as the pioneer of Blue revolution. He spent his entire life in developing sustainable aquaculture and freshwater fish farming as an alternative solution to the food crisis of the future. These techniques are not only sustainable but also environment friendly, incorporating use of agricultural wastes and by-products along with innovative practices. Poverty, malnutrition and selfreliance were addressed effectively with this technique. He enthusiastically taught these methods to the rural women with low levels of income and social status, leading to enhancement of their rights and truly empowering them, financially and socially. It may be placed on record, his voluminous service in war-torn conflict areas, risking his own life. Farmers and consumers, looking towards recovery from the Vietnam War was an example of direct beneficiaries of this unique technique. He trained farmers and scientists to breed new species and identified new carp species that were native to India but suitable to the Mekong River environment in Southeast Asia. He was thus able to create a solution that solved problems of population explosion and impacts of climate change.

His methodology basically involved three things:

- Worked at the grassroots level with the farmers to understand their unique situations and devise methods to implement fish farming. 
- Integrated his working with the local NGOs to better connect with the people and help in financial access and overcome other bottlenecks in implementation.

- Enabled women empowerment that led to a chain of positive reinforcements at the family level and the future generations.

Some of the qualities that are clearly visible in his way of working are:

- Optimistic

- Willing to change

- Focused on solutions

- Build Trust

- Collaborate towards cohesiveness

- Keeping everyone engaged in collectively meeting the end goal

- Direct communication

- $\quad$ Never Give up

These may sound to be managerial qualities but in fact they are leadership qualities of a different genre. There is a subtle line dividing the concept of boss and leader. Similarly, there is a difference between 'lead by giving orders' and 'lead by working alongside.' Dr Gupta had a unique style that was powerful by being quietly understated.

\section{Bottom-up Approach}

"Generally, research is undertaken in research institutions/organizations and then efforts are made to transfer the results to the farming community - which some people call as "top-down approach". Under such circumstances it has been often found that the technologies so developed do not meet the needs of the farming community as the scientists have taken in to consideration only the biological aspects of increased production and have not considered the social, economic and cultural aspects of the farming community for whom these technologies are meant. Dr Gupta's approach applied a "bottom-up" approach that involved understanding the social, economic and cultural aspects of the community, their resources and constraints (physical, technical, financial) and then plan research taking in to consideration all the above mentioned aspects. The adoption of technology is quicker as the technology developed suited the needs of the farmer.

For this to take place the methodology used was:

(i) Had a group meeting with the farmers to understand their economic situation, technical knowledge, their needs and constraints

(ii) Explained the technologies that could be suitable for them and got feed back from them on the relevance of the suggested technology, modified to suit their needs based on discussion;

(iii) Undertook research in their farms, called "on-farm research" or "farmer participatory research". Once the technology under farmers' conditions was demonstrated, then not much effort is needed by government agencies (extension department) for transfer of technology as nearby farmers saw the results for themselves and tried the technology - farmer to farmer extension.

His working at grassroots level with farmers made some people in the early stages dubbing him as a development worker rather than a scientist/researcher. His only response to them was "I am a development researcher" and my research is not for research sake, but for development. They understood later, after seeing the impact the research had made and was being followed in many countries. As he was doing things that were not conventional, some people even dubbed him as rebel scientist" Dr Gupta also worked with NGOs to help motivate and train the farmers, besides establishing a trust factor. He was strong in science (biological aspects) and the NGOs working at the grassroots level knew more about social, economic and cultural aspects of farming communities. Joining hands with NGOs resulted in bringing together the strengths of the NGOs and him.

Another positive aspect from this collaborative effort was sustainability. In general practice, whenever a research institute developed a technology, it was demonstrated in farmers' facilities by giving them free inputs in addition to technical knowledge. The drawback in such a system was once the free inputs from government agencies was over, the farmers would go back to their own practices. This was because the farmer who was getting free inputs would not understand the real economic value of the technology and did not have access to the needed inputs. An integrated way of working was when he looked toward empowering the women with his pioneering work. He worked with NGOs to establish trust, especially in the conservative Islamic culture of Bangladesh and trained women in aqua farming. It was successful to the extent that men also started learning the art of fish culture. His work with women showed that making women earning members not only lead to a status in the family and society, Women had a voice in deciding household management after this. The families' 
nutritional status improved and women were spending on children's education - a multi benefit. To conclude, the innovative leadership style of Dr M.V.Gupta has proven to be a style of his own, created and formatted along the way, not out of textbooks and managerial concepts but straight from the fields, emerging out of actual practice. It is a style that is inherently his and lessons can be learnt from this unique experience, which has transformed populations and help civilizations come out of poverty.

This is no 'corporate' style that has evolved out of boardrooms, mouthed by pinstripe suited management graduates but a simple and gentle soul who worked simply to putting use his scientific expertise to practice. In an age where scientific research is funded and conducted in labs with no guaranteed practical use, here is a humble person with true Gandhian values who has created a leadership without barriers and a new style of working at the grassroots level, the bottom-up approach. As far asaqua farming is concerned, it can be implemented in any place on the earth. It is not dependent on coastal requirements but a 'contained water source' as simple as a pond. This method of working can be adopted in any work place culture, and will surely produce excellent results as it basically involves working with your team. A true leader 'leads by example' and with the people.

\section{Other notable achievers in social innovations}

Anil Gupta, the Founder of Honeybee Network and the National Innovation Foundation has been scouting the rural areas and collecting various innovations (more than 1, 40,000 innovations) done at the grassroots level. They provide institutional support towards streamlining the manufacturing processes, the intellectual property rights in order to make the rural people into self-sustaining entrepreneurs. Rikin Gandhi, CEO of Digital Green which is a Mocrosoft Research India Project helps to increase productivity of small farmers. They video tape agricultural improvements by small farmers and show them in other villages. Marico, the company that produces Parachute brand of coconut oil, discovered a coconut-tree climbing device made by a Kerala farmer. They helped in making a prototype of this and distributed it to villagers across the country that increased productivity. Villgro, a Chennai-based company is another such that has promoted more than 1500 innovations and transformed lakhs of villagers into efficient methods of production.

\section{Final Note on Policy Initiatives on Skills India Development}

Post independence, after 68 years a Ministry for Skill Development \& Entrepreneurship (MSDE) has been formed towards increasing employability through skill development. 20 lakh people have so far been trained in this project wherein vocational education and training have been imparted. For the first time in 68 years of India's independence, a Ministry for Skill Development \& Entrepreneurship (MSDE) has been formed to focus on enhancing employability of the youth through skill development. The skill ecosystem in India, is seeing some great reforms and policy interventions which is reinvigorating and re-energising the country's workforce today; and is preparing the youth for job and growth opportunities in the international market. The Hon'ble Prime Minister's flagship scheme, PradhanMantriKaushalVikasYojana (PMKVY) alone, has till date seen close to 20 lakh people get skilled and prepared for a new successful India. Skill India harbours responsibility for ensuring implementation of Common norms across all skill development programs in the country so that they are all standardized and aligned to one object. The ITI ecosystem has also been brought under Skill India for garnering better results in vocational education and training. The Directorate General of Training (DGT), National Skill Development Agency (NSDA), National Skill Development Corporation (NSDC) and National Skill Development Fund (NSDF), Indian Institute of Entrepreneurship (IIE), National Institute of Entrepreneurship and Small Business Development (NIESBUD), Skills Sector Council (SSC) are few of the organizations that are focused on taking this movement forward. There are several more continuously engaged in promoting innovations at the rural level. All these go to prove that each scientist or social worker has a different methodology and approach but all are striving towards empowering the villager, and implementing social innovations.

\section{Acknowledgement}

The authors acknowledge with a deep sense of respect and gratitude the insights gathered from the inputs provided by Dr M V Gupta, who is hailed as the Pioneer of Blue Revolution and the recipient of the World Food Prize in 2005 considered as Nobel Prize in Food and Agriculture and the Sunhak Peace Prize in 2015. It was a privilege and honour to write about this eminent personality. 


\section{References}

[1] Wikipedia, (2016). Modadugu Vijay Gupta. [online] Available at: https://en.wikipedia.org/wiki/Modadugu_Vijay_Gupta [Accessed 16 Jan. 2016].

[2] The Economic Times, (2016). Noted Indian scientist Dr Modadugu Vijay Gupta awarded first Sunhak Peace Prize - The Economic Times. [online] Available at: http://economictimes.indiatimes.com/news/science/noted-indian-scientist-dr-modadugu-vijay-guptaawarded-first-sunhak-peace-prize/articleshow/48708810.cms [Accessed 16 Jan. 2016].

[3] Currentaffairs.gktoday.in, (2016). Scientist Dr Modadugu Vijay Gupta to receive inaugural Sunhak Peace Prize. [online] Available at:http://currentaffairs.gktoday.in/scientist-dr-modadugu-vijay-gupta-receive-inaugural-sunhak-peace-prize-08201526198.html [Accessed 16 Jan. 2016].

[4] Sunhakprize.com, (2016). SUNHAK PEACE PRIZE. [online] Available at: http://sunhakprize.com/eng/sp.php?p=24 [Accessed 16 Jan. 2016]

[5] Indian, T. (2015). Indian Scientist Dr Modadugu Vijay Gupta Awarded First Sunhak Peace Prize. [online] The Logical Indian. Available at: http://thelogicalindian.com/story-feed/achievers/indian-scientist-dr-modadugu-vijay-gupta-awarded-first-sunhakpeace-prize/ [Accessed 16 Jan. 2016].

[6] Global Reach Internet Productions, I. (2016). [online] Worldfoodprize.org. Available at: https://www.worldfoodprize.org/en/laureates/20002009_laureates/2005_gupta/ [Accessed 16 Jan. 2016]

[7] Fao.org, (2016). Manual on polyculture and integrated fish farming in Bangladesh. [online] Available at: http://www.fao.org/docrep/field/003/ac375e/AC375E03.htm [Accessed 16 Jan. 2016]

[8] Modern Farming Methods, (2012). Fish Polyculture | Modern Farming Methods. [online] Available at: http://www.roysfarm.com/fish-polyculture/ [Accessed 16 Jan. 2016].

[9] Fao.org, (2016). Manual on polyculture and integrated fish farming in Bangladesh. [online] Available at: http://www.fao.org/docrep/field/003/ac375e/ac375e00.htm [Accessed 16 Jan. 2016].

[10] Epubs.icar.org.in, (2016). [online] Available at: http://epubs.icar.org.in/ejournal/index.php/IJF/article/viewFile/6762/2564 [Accessed 16 Jan. 2016].

[11] Anon, (2016). [online] Available at: http://www.indiawaterportal.org/sites/indiawaterportal.org/files/Inland\%20culture\%20fisheries\%20in\%20village\%20tanks\%20and $\% 20$ ponds_\%20A\%20multilocation\%20study\%20in\%20India_Santanu\%20Ghosh\%20and\%20Rajnarayan\%20Indu_CAREWATE R.pdf [Accessed 16 Jan. 2016].

[12] Developmentbookshelf.com, (2016). [online] Available at: http://www.developmentbookshelf.com/doi/pdf/10.3362/17551986.2015.006 [Accessed 16 Jan. 2016].

[13] Cabannes, Y. (2012). Financing urban agriculture. Environment and Urbanization, 24(2), pp.665-683.

[14] Wikipedia, (2016). Aquaculture. [online] Available at: https://en.wikipedia.org/wiki/Aquaculture [Accessed 18 Jan. 2016].

[15] Schwabfound.org, (2016). What is a social entrepreneur? | Schwab Foundation for Social Entrepreneurship. [online] Available at: http://www.schwabfound.org/content/what-social-entrepreneur [Accessed 18 Jan. 2016].

[16] Ashoka.org, (2016). What is a Social Entrepreneur? | Ashoka - Innovators for the Public. [online] Available at: https://www.ashoka.org/social_entrepreneur [Accessed 18 Jan. 2016].

[17] Wikipedia, (2016). Social entrepreneurship. [online] Available at: https://en.wikipedia.org/wiki/Social_entrepreneurship [Accessed 18 Jan. 2016].

[18] Fao.org. (2016). FAO Food Price Index | FAO | Food and Agriculture Organization of the United Nations. [online] Available at: http://www.fao.org/worldfoodsituation/foodpricesindex/en/ [Accessed 16 Mar. 2016].

[19] Prahalad, C. \& Hart, S. (2002). The Fortune at the Bottom of the Pyramid. strategy+business. Retrieved 19 July 2016, from http://www.strategy-business.com/article/11518?gko=9a4ba

[20] Francis, Ierene. "Prof. Anil Gupta: 'Grassroot Innovation Is Alive And Well In India, We Just Have To Look For It'". The Alternative. N.p., 2014. Web. 12 Feb. 2017.

[21] "India's Rural Inventors Drive Change | SRISTI". Sristi.org. N.p., 2017. Web. 10 Feb. 2017

[22] "About Us - Villgro". Villgro. N.p., 2017. Web. 3 Jan. 2017.

[23] Suryakumari, D., S. Deshpande, and V. Deshpande. "The Relevance Of Appreciative Inquiry In The Context Of Social Change, Social Research, Social Work And Social Entrepreneurship". Imperialjournals.com. N.p., 2017. Web. 10 Aug. 2016. 